\title{
Dimensioning of a railway station for unknown operation
}

\author{
O. Lindfeldt \& A.-I. Lundberg \\ Division of Traffic and Logistics, Department of Transport and \\ Economics, Royal Institute of Technology, Stockholm, Sweden
}

\begin{abstract}
Every now and then new railway stations are brought into operation on existing lines. This is a good way of increasing the availability of railway services and attracting more passengers. However, from a capacity point of view, this procedure can be quite tricky, since new stations and additional stops thoroughly alter the traffic properties of the line.

The addition of a station like this in Solna, north of Stockholm is under discussion. Here, most of the regional trains, but probably not the long-distance trains, would stop for passenger exchange. A new line, connected to the main line just north of Solna, would also contribute to the traffic flow through the new regional station.

The essential question in this project was to determine the number of platform tracks needed to cope with the traffic flow. However, it has proven difficult to find a representative timetable structure to use in the dimensioning work, both the total number of trains and the distribution between stopping and passing trains turned out to be uncertain.

A combinatorial method was therefore applied. Using this approach, a large number of timetables, i.e. possible traffic situations, were generated and tested (automatically) for the number of platform tracks needed.

Constructing and using this simple model forced the engineers to understand and describe the fundamentals of this operational/scheduling/dimensioning problem. The procedure hence gave useful insights about the system properties and a direct knowledge of the sensitivity of different factors that are essential for the number of tracks needed at a railway station like this.
\end{abstract}

Keywords: station design, station capacity, timetable, combinatorial method. 


\section{Introduction}

Every now and then railway stations are added and brought into operation on existing lines. This is a good way of increasing the availability of railway services and attracting more passengers. As with most investments in railway infrastructure, this type of extension is much easier to dimension correctly when the future timetable is known, or can be decided, before the station is designed.

A special case is dedicated commuter lines with completely homogeneous traffic. In these cases, all trains can be assumed to stop for passenger exchange at the new station. The design, i.e. track and platform configuration etc, is therefore merely a question of frequency of service, dwell times and delays. The exact timetable is less important and the station's operation can be assumed to be similar to that of already existing, adjacent stations.

However, most Swedish railway lines are operated with mixed traffic. Longdistance, regional and freight trains are mixed. The construction of additional stations on these lines implies great uncertainties connected to the timetable. The track configuration, including the number of platform tracks, parallel movement facilities etc, has to be carefully designed so that the overall capacity is not affected negatively by the new station.

When the traffic is mixed, it is not so easy to foresee which trains are going to stop and which are not. Even if the number of stopping trains per timetable cycle is known, it is also necessary to know the exact sequence of stopping and passing trains to achieve a proper station design.

Stockholm Central station is a combined through and dead-end station served by two major lines from the north and one from the south. The two north lines, the East Coast line and the Mälar line, are quadruple- and double-track respectively. On the four-track East Coast line, the commuter traffic is separated from other traffic whereas the two-track Mälar line is operated with a full mix of traffic.

This mix of different speeds limits capacity and implies a high level of disturbance sensitivity on the Mälar line. The demand for more and reliable traffic motivates an extension into quadruple track and planning is currently ongoing. Two alternative locations of the two new tracks have been evaluated:

- Along existing tracks all the way from Kalhäll to the junction in Tomteboda.

- Along existing tracks from Kalhäll to Barkarby and then through a tunnel eastwards to the East Coast line, see figure 1.

The second alternative, which also implies an extension into six tracks of the East Coast line south of the junction in Ulriksdal, also gives the opportunity to extend the existing Solna commuter station into a combined station for commuter and regional trains. Such a station would serve both commuter and regional traffic from the East Coast line and regional traffic from the Mälar line, whereas commuter traffic on the Mälar line would continue to use the old line through Sundbyberg. 


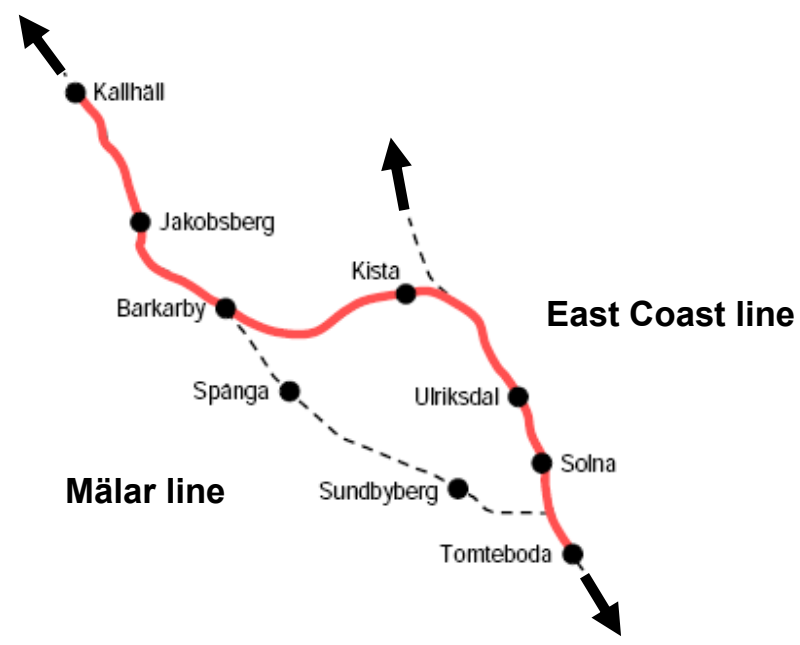

Stockholm C

Figure 1: Extension of Mälar line through a tunnel between Barkarby and the East Coast line.

This type of complex system gives rise to several questions regarding how the extended station should be designed to give sufficient capacity and other operational properties. This article describes a deterministic method that systematically evaluates different timetable layouts, i.e. combinations of frequency of service and stopping/passing patterns. Solna station is used to exemplify the method since the conditions are clear and the traffic situation is neither too simple nor too complex for this kind of analysis.

This introduction is followed by a short overview of related studies and literature. The section "Method and modelling" then describes conditions and assumptions regarding infrastructure design, timetable generation, and the capacity allocation model. The results are then presented, followed by some concluding ideas about the proposed way of modelling and further developments.

\section{Related studies and literature}

The Stockholm area has undergone several infrastructure planning processes during the last decade. Lindfeldt [5] gives an overview of different capacity issues that were faced during the design of the new commuter line, Citybanan, through Stockholm. The evaluation method applied for the two connecting junctions has several similarities with the method presented in this article. Also in these cases, the design had to be performed subject to uncertainties about future timetables and operation.

Berg von Linde [1] evaluates the unfavourable interaction of two closely located bottlenecks south of Stockholm Central station. One of these bottlenecks, 
Flemingsberg station, has only one platform track for north-bound traffic and this imposes considerable constraints on the timetable.

Lindfeldt [7] also makes use of combinatorial methods to evaluate a great number of timetable variants for mixed traffic on double-track lines. He uses these methods to analyse the effect of frequencies of service, speeds and distances between overtaking stations on line capacity. Also here, the idea is to determine the interrelations between infrastructure and timetable.

Schaafsma and Bartholomeus [8] present a new control concept for the Schiphol bottleneck in the Netherlands. Schiphol has several similarities with the planned Solna station. Both are located between two junctions, have several platform tracks, dense traffic and high utilisation. Several operation procedures that are already in use at Schiphol, e.g. the first come first served operation, the cross platform strategy and the stay in lane principle, will all be applicable at a future Solna station as well. These procedures can be brought to maximal efficiency if the infrastructure design is performed with them in mind.

Several studies have been made of routing through existing stations and alternative methods are proposed in the literature. Hansen [3] gives a clear introduction to the complexity of train routing through stations. He compares analytical approaches based on queuing theory and max-plus algebra respectively. He concludes that these methods give similar results regarding the location of bottlenecks and the occupation of route sections. However, significant differences in the amount of buffer time and the ability of the track network to compensate for delays call for further development of both methods.

Yuan and Hansen [9] propose a sophisticated method of determining station capacity indirectly through estimation of knock-on delays caused by route conflicts. Their model takes into account variations in track occupancy times due to fluctuations in train speeds, varying dwell times etc.

Kroon et al. [4] face the computational complexity of the problem of routing trains through railway stations. They show that when the layout of a railway station is fixed the amount of computational time is polynomial in the number of trains.

Carey and Carville [2] consider the problem of routing trains through large, busy stations. They use scheduling heuristics similar to those adopted by train planners using manual methods. They are hereby able to include rules, costs and preferences used by the expert planners. The method is similar to that described in this article since the trains are slotted one by one according to their desired arrival times.

None of the reviewed papers explicitly focuses on the designing of infrastructure or how the requirements regarding station design depend on the traffic situation, which is the main objective in this article.

\section{Method and modelling}

The design of a railway station depends strongly on operational factors such as timetable, disturbances (delays) and occurrence of shunting movements etc. This study aims to explicitly show how the timetable affects the number of tracks 
needed at a through station that is operated with a mix of stopping and passing trains arriving from two independently operated lines. For the sake of simplicity, no disturbances are taken into account and all kinds of process times and headway times are assumed to be deterministic. All modelled trains are assumed to have approximately the same characteristics such as speed, retardation, acceleration, dwell times etc.

\subsection{Infrastructure}

A simplified schematic track layout is shown in figure 2. Stockholm Central station is located to the left, connected to four tracks above ground and two underground tracks dedicated for commuter traffic (still under construction). This commuter line (City line) and the (existing) Mälar line are both connected to the East Coast line at Tomteboda, whereas the two new tracks for Mälar line are planned to be connected at a junction further north (to the right). Solna station is located between these junctions and the objective of this article is to find a feasible track layout for this station.

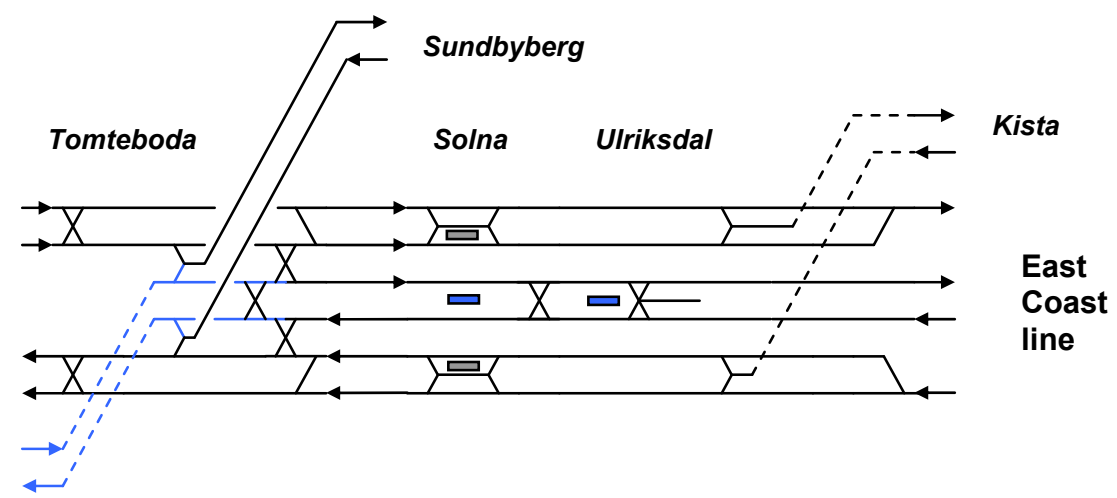

Figure 2: $\quad$ Infrastructure layout.

One important condition for the operation is that the two middle tracks are dedicated for commuter trains on the East Coast line, so the task is to find the number of platform tracks connected to the two-line tracks on each side of the commuter tracks in the middle. Due to symmetries in the operation and the surrounding infrastructure, it is reasonable to also assume symmetry in the station design.

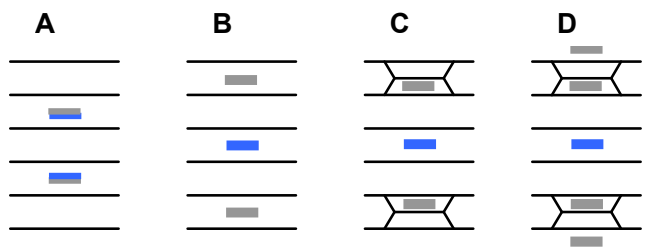

Figure 3: Possible station designs. The two mid-tracks are dedicated for commuter traffic and are not evaluated in this study. 
Figure 3 shows four possible configurations with one, two and three platform tracks for non-commuter trains in each direction. Depending on the number of passing trains, it might be feasible to construct tracks without platforms, alternatives $\mathrm{A}$ and $\mathrm{C}$.

\subsection{Timetables and timetable generation}

The station design depends on several timetable factors, mainly the number of trains operated on each line per time unit. These numbers are unknown, or uncertain, during the planning process. The situation is made even more difficult since neither the distribution between stopping and passing trains can be predicted.

The method described below is one way to evaluate how different timetables affect the number of platform tracks needed. Combinatorial methods are used to generate all possible timetable variants that follow from a few basic assumptions. This is done in two steps. First, a traffic situation is defined by four factors:

- Total number of trains/h on East Coast line.

- Number of stopping trains/h on East Coast line.

- Total number of trains/h on Mälar line.

- Number of stopping trains/h on Mälar line.

Several timetable variants may correspond to each traffic situation. These timetable variants arise because:

- Stopping trains on the East Coast line can be chosen in different ways from the total number of trains on this line.

- Stopping trains on Mälar line can be chosen in different ways from the total number of trains on this line.

- The phase shift between the timetables for the two lines can be varied.

For a given traffic situation the total number of timetable variants is given by:

$$
N_{\text {timetable }}=\left(\begin{array}{l}
N_{E C} \\
n_{E C}
\end{array}\right) *\left(\begin{array}{l}
N_{M} \\
n_{M}
\end{array}\right) * f=\frac{N_{E C} !}{n_{E C} !\left(N_{E C}-n_{E C}\right) !} * \frac{N_{M} !}{n_{M} !\left(N_{M}-n_{M}\right) !} * f
$$

In eqn (1) $n_{i}$ denotes the number of stopping trains and $N_{i}$ the total number of trains on a line $i . f$ is the number of phase shifts between the timetables of the two lines.

Different traffic situations give rise to different numbers of timetable variants. Based on demand forecasts and experience from earlier operation, four basic assumptions were made in order to limit the evaluation space:

- Total number of trains on East Coast line: $14-18$ trains $/ \mathrm{h}$.

- Total number of trains on Mälar line: 4-8 trains/h.

- The traffic pattern is repeated every 30 minutes and so the period of evaluation is limited to 30 minutes. This also implies that 30 different relative time shifts between the timetables of the lines appear, $f=30$ in eqn (1).

- Arriving trains are evenly spread on each line.

Table 1 shows the number of timetables that arise in each traffic situation when these assumptions are combined with different numbers of stopping trains. 
Each cell corresponds to a traffic situation. The first column shows a pair of numbers on each row. These are the total number of trains/h on the Mälar line and how many of these stop at Solna station. In the same way, the lowest row shows the corresponding data for the East Coast line. It can be seen that each traffic situation consists of $30-15120$ timetable variants.

Table 1: $\quad$ Number of timetable variants for different traffic situations.

\begin{tabular}{|c|c|c|c|c|c|c|c|c|c|c|c|}
\hline $\begin{array}{l}8 \\
8\end{array}$ & 30 & 630 & 630 & 30 & 30 & 2100 & 30 & 30 & 2520 & 2520 & 30 \\
\hline \begin{tabular}{|l}
8 \\
4 \\
\end{tabular} & 180 & 3780 & 3780 & 180 & 180 & 12600 & 180 & 180 & 15120 & 15120 & 180 \\
\hline $\begin{array}{l}8 \\
0 \\
\end{array}$ & 30 & 630 & 630 & 30 & 30 & 2100 & 30 & 30 & 2520 & 2520 & 30 \\
\hline $\begin{array}{l}6 \\
6\end{array}$ & 30 & 630 & 630 & 30 & 30 & 2100 & 30 & 30 & 2520 & 2520 & 30 \\
\hline $\begin{array}{l}6 \\
4 \\
\end{array}$ & 90 & 1890 & 1890 & 90 & 90 & 6300 & 90 & 90 & 7560 & 7560 & 90 \\
\hline $\begin{array}{l}6 \\
2 \\
\end{array}$ & 90 & 1890 & 1890 & 90 & 90 & 6300 & 90 & 90 & 7560 & 7560 & 90 \\
\hline $\begin{array}{l}3 \\
0 \\
\end{array}$ & 30 & 630 & 630 & 30 & 30 & 2100 & 30 & 30 & 2520 & 2520 & 30 \\
\hline $\begin{array}{l}4 \\
4\end{array}$ & 30 & 630 & 630 & 30 & 30 & 2100 & 30 & 30 & 2520 & 2520 & 30 \\
\hline $\begin{array}{l}4 \\
2 \\
\end{array}$ & 60 & 1260 & 12060 & 60 & 60 & 4200 & 60 & 60 & 5040 & 5040 & 60 \\
\hline $\begin{array}{l}4 \\
0\end{array}$ & 30 & 630 & 630 & 30 & 30 & 2100 & 30 & 30 & 2520 & 2520 & 30 \\
\hline & $\begin{array}{c}14 \\
0\end{array}$ & $\begin{array}{c}14 \\
4\end{array}$ & $\begin{array}{l}14 \\
10\end{array}$ & $\begin{array}{l}14 \\
14\end{array}$ & $\begin{array}{c}16 \\
0\end{array}$ & $\begin{array}{c}16 \\
8\end{array}$ & $\begin{array}{l}16 \\
16\end{array}$ & $\begin{array}{c}18 \\
0\end{array}$ & $\begin{array}{c}18 \\
6\end{array}$ & $\begin{array}{l}18 \\
12\end{array}$ & $\begin{array}{l}18 \\
18\end{array}$ \\
\hline
\end{tabular}

East Coast line

\subsection{Capacity allocation procedure}

Each timetable variant implies a unique pattern of station capacity that is required for conflict-free operation. The utilisation of each platform track is heavily dependent on the headway times that are applied during timetable construction. Ideally, these times should be chosen with regard to the prevailing delay level and the acceptance for knock-on delays (Yuan and Hansen [9]). For the sake of simplicity, the values below are applied in this study. They correspond to values commonly used in Swedish planning (Berg von Linde [1]).

- Minimum timetable headway times:

- 200 s outside platform block sections.

- $300 \mathrm{~s}$ on platform block sections after stopping trains.

○ $200 \mathrm{~s}$ on platform block sections after passing trains.

- Reaction time and time supplement for acceleration for stopping trains is $60 \mathrm{~s}$. This time is only applied when a stopping train is followed by a passing one.

Using these headway times the number of platform tracks can be estimated for each timetable variant through a direct track allocation procedure programmed in MATLAB. The trains are simply assigned to platform tracks in the order they arrive (first in first served), cf. Carey and Carville [2]. The model endeavours to choose the lowest available track number which results in efficient utilisation and a minimum number of tracks. 
This type of capacity allocation was performed both for the platform tracks and for the exit tracks. It is important to also check the exit tracks since some timetable variants might result in an exit flow of trains that requires more than two line tracks beyond the station.

\section{Results}

Different performance evaluations are possible. The calculations result in a discrete distribution of tracks needed for each traffic situation. These distributions might most conveniently be represented by mean and standard deviation measures. Together they give an idea of the required number of tracks for each traffic situation.

The exact track utilisation can also be plotted for traffic situations of special interest. Such a plot shows both the number of tracks needed for each timetable variant and their degree of utilisation.

Throughout the study all station tracks have been modelled as platform tracks. It is therefore impossible to tell whether some of the tracks can be constructed without platforms, i.e. for passing trains only, or not. Such an analysis requires additional modelling.

\subsection{Platform tracks}

Table 2 shows the mean number of required platform tracks for the studied traffic situations. Bear in mind that the calculation includes only tracks dedicated for long-distance and regional traffic in one direction. The entire design is given by symmetry assumptions and the fact that two mid-tracks are dedicated for commuter traffic.

The values in table 2 are mean numbers of tracks needed for the timetables that originate from each traffic situation. For example, the traffic situation ${ }_{4}^{14}+\frac{6}{4}$

Table 2: $\quad$ Mean number of required platform tracks.

\begin{tabular}{|c|c|c|c|c|c|c|c|c|c|c|c|}
\hline $\begin{array}{l}8 \\
8\end{array}$ & 2 & 2.96 & 3 & 3 & 2 & 2.99 & 3 & 2 & 3 & 3 & 3 \\
\hline $\begin{array}{l}8 \\
4 \\
\end{array}$ & 2 & 2.90 & 3 & 3 & 2 & 2.99 & 3 & 2 & 2.99 & 3 & 3 \\
\hline $\begin{array}{l}8 \\
0\end{array}$ & 2 & 2.81 & 3 & 3 & 2 & 2.99 & 3 & 2 & 2.98 & 3 & 3 \\
\hline $\begin{array}{l}6 \\
6 \\
\end{array}$ & 2 & 2.84 & 3 & 3 & 2 & 2.99 & 3 & 2 & 2.96 & 3 & 3 \\
\hline $\begin{array}{l}6 \\
4 \\
\end{array}$ & 2 & 2.78 & 3 & 3 & 2 & 2.98 & 3 & 2 & 2.94 & 3 & 3 \\
\hline $\begin{array}{l}6 \\
2 \\
\end{array}$ & 2 & 2.73 & 2.99 & 3 & 2 & 2.97 & 3 & 2 & 2.91 & 3 & 3 \\
\hline $\begin{array}{l}6 \\
0 \\
\end{array}$ & 2 & 2.67 & 2.99 & 3 & 2 & 2.96 & 3 & 2 & 2.85 & 2.99 & 3 \\
\hline $\begin{array}{l}4 \\
4\end{array}$ & 2 & 2.63 & 2.98 & 3 & 2 & 2.90 & 3 & 2 & 2.85 & 2.99 & 3 \\
\hline $\begin{array}{l}4 \\
2 \\
\end{array}$ & 2 & 2.56 & 2.95 & 3 & 2 & 2.88 & 3 & 2 & 2.78 & 2.98 & 3 \\
\hline $\begin{array}{l}4 \\
0\end{array}$ & 2 & 2.48 & 2.91 & 3 & 2 & 2.81 & 3 & 2 & 2.71 & 2.96 & 3 \\
\hline & $\begin{array}{c}14 \\
0\end{array}$ & $\begin{array}{c}14 \\
4\end{array}$ & $\begin{array}{l}14 \\
10\end{array}$ & $\begin{array}{l}14 \\
14\end{array}$ & $\begin{array}{c}16 \\
0\end{array}$ & $\begin{array}{c}16 \\
8\end{array}$ & $\begin{array}{l}16 \\
16\end{array}$ & $\begin{array}{c}18 \\
0\end{array}$ & $\begin{array}{c}18 \\
6\end{array}$ & $\begin{array}{l}18 \\
12\end{array}$ & $\begin{array}{l}18 \\
18\end{array}$ \\
\hline
\end{tabular}


needs 2.78 platform tracks. This means that two tracks are enough in $22 \%$ of the available timetables for this traffic situation, whereas three tracks are needed in $78 \%$ of the timetables. In this traffic situation it is reasonable to believe that a two-tracked station would impose restrictions on the timetable or cause scheduled delays due to lack of station capacity.

The table shows several interesting results. First, no timetable variant in the 110 examined traffic situations needed fewer than two or more than three platform tracks. The design question is therefore limited to a choice between two and three tracks/direction. It is also clear that stopping trains on the East Coast line are those who impose a need for a third track.

Traffic situations with a mean lower than 2.75 tracks are marked in the table. These are borderline cases where either two platform tracks or two platform tracks and one passing track without a platform could be considered. These alternatives imply lower investment costs at the cost of additional timetable constraints and/or scheduled delays.

The validity of the calculated values provides that all conditions and assumptions are correct. The most important assumption is probably that each platform track can be utilised every 300 seconds. Such operation requires relatively high punctuality. Under Swedish circumstances, with long delays and low punctuality, the presented values for the number of tracks needed are rather underestimations.

For traffic situations of special interest it is also useful to study the track utilisation in detail. One such example is shown in figure 4. Since the model systematically chooses a lower track whenever possible, the utilisation will always be highest for track 1 and lowest for track 3 . Note that there are timetable variants $(\sim 40 \%)$ that do not need a third track. For these timetables the utilisation is higher for track 1 and/or 2 .

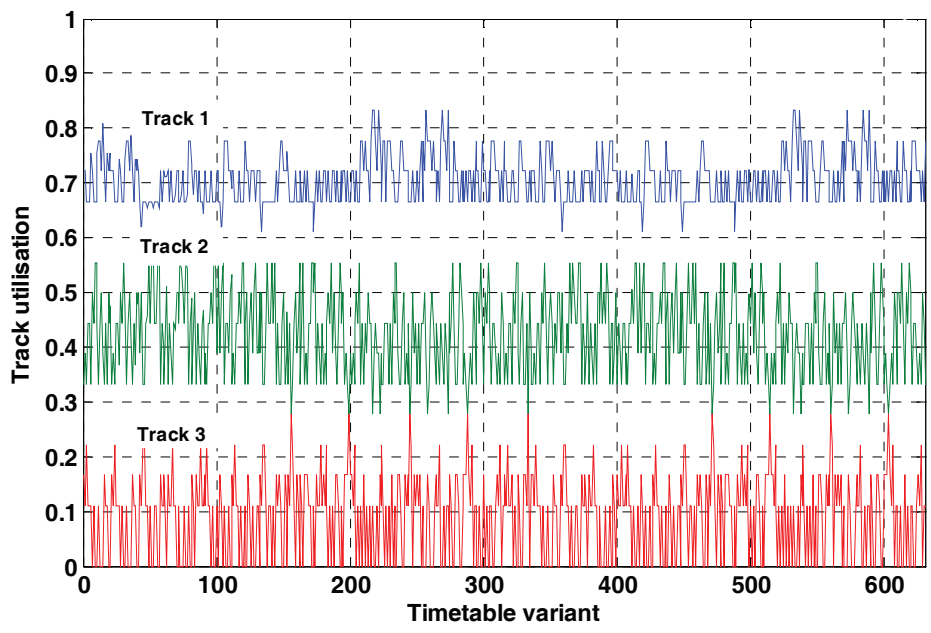

Figure 4: Track utilisation for timetables originating from the traffic situation $14+4$

44 


\subsection{Exit tracks}

A station consists of platform tracks and entrance and exit track sections leading into and out of the station. The station analysed in this article is actually a rather simple through station located between two junctions. The number of entrance tracks is the same as the number of connecting lines. This fact, together with relatively low utilisation of the Mälar line, indicates that the conflicts on the entrance side will be limited and that it is reasonable to assume all arrivals to be conflict-free.

Due to the mix of stopping and passing trains the situation will be different on the exit side of the station. On this side, the traffic flow will be less regular and so conflicts may occur that need a third track to be resolved. It is therefore also of interest to check the exit capacity.

Table 3 shows the share of timetable variants within each traffic situation that could be scheduled conflict-free with only two exit tracks. Two exit tracks are enough in cases where all trains stop or all trains pass. This is reasonable since the exit flow of trains will then be identical to the entrance flow.

Table 3: Share of timetable variants where two exit tracks are enough. Traffic situations lower than 0.20 marked.

\begin{tabular}{|c|c|c|c|c|c|c|c|c|c|c|c|}
\hline $\begin{array}{l}8 \\
8\end{array}$ & 1 & 0,37 & 0,36 & 1 & 1 & 0,1 & 1 & 1 & 0,13 & 0,18 & 1 \\
\hline $\begin{array}{l}8 \\
4\end{array}$ & 0,2 & 0,12 & 0,15 & 0,31 & 0,17 & 0,13 & 0,33 & 0,17 & 0,097 & 0,1 & 0,33 \\
\hline $\begin{array}{l}8 \\
0\end{array}$ & 1 & 0,25 & 0,06 & 1 & 1 & 0,056 & 1 & 1 & 0,083 & 0,034 & 1 \\
\hline $\begin{array}{l}6 \\
6 \\
\end{array}$ & 1 & 0,5 & 0,53 & 1 & 1 & 0,26 & 1 & 1 & 0,31 & 0,23 & 1 \\
\hline $\begin{array}{l}6 \\
4 \\
\end{array}$ & 1 & 0,5 & 0,46 & 1 & 1 & 0,33 & 1 & 1 & 0,31 & 0,32 & 1 \\
\hline $\begin{array}{l}6 \\
2\end{array}$ & 1 & 0,47 & 0,36 & 1 & 1 & 0,29 & 1 & 1 & 0,29 & 0,27 & 1 \\
\hline $\begin{array}{l}3 \\
0\end{array}$ & 1 & 0,41 & 0,26 & 1 & 1 & 0,26 & 1 & 1 & 0,31 & 0,23 & 1 \\
\hline $\begin{array}{l}2 \\
2 \\
\end{array}$ & 1 & 0,63 & 0,64 & 1 & 1 & 0,54 & 1 & 1 & 0,49 & 0,51 & 1 \\
\hline $\begin{array}{l}2 \\
1\end{array}$ & 1 & 0,6 & 0,52 & 1 & 1 & 0,48 & 1 & 1 & 0,48 & 0,45 & 1 \\
\hline $\begin{array}{l}2 \\
0\end{array}$ & 1 & 0,59 & 0,46 & 1 & 1 & 0,48 & 1 & 1 & 0,48 & 0,43 & 1 \\
\hline & $\begin{array}{c}14 \\
0\end{array}$ & $\begin{array}{c}14 \\
4\end{array}$ & $\begin{array}{l}14 \\
10\end{array}$ & $\begin{array}{l}14 \\
14\end{array}$ & $\begin{array}{c}16 \\
0\end{array}$ & $\begin{array}{c}16 \\
8\end{array}$ & $\begin{array}{l}16 \\
16\end{array}$ & $\begin{array}{c}18 \\
0\end{array}$ & $\begin{array}{c}18 \\
6\end{array}$ & $\begin{array}{l}18 \\
12\end{array}$ & $\begin{array}{l}18 \\
18\end{array}$ \\
\hline
\end{tabular}

East Coast line

Low values are shown for traffic situations with a mix of stopping and passing trains. Some of these will hardly manage without a third exit track or added scheduled delays through extended dwell or passing times. The conclusion is that combinations where half of the trains from both lines stop are the most difficult to schedule with only two exit tracks. However, serious problems do not occur until the Mälar line is operated by more than 6 trains $/ \mathrm{h}$. 


\section{Conclusions and further work}

This article proposes a heuristic approach to find a feasible design for a railway station whose future operation, i.e. number of stopping and passing trains, is uncertain. The results show that three platform tracks/direction are needed to accommodate long-distance and regional traffic, even for moderate traffic intensities.

Further studies are recommended to determine whether one of these platform tracks could be replaced by a track without a platform, to be used by passing trains only. A separate analysis of the sensitivity to assumed headway times is also to be considered.

The modelling of timetables could be extended to also take into account less regularity in the arrival processes. Such timetables are more realistic due to speed differences between trains, operation of adjacent bottlenecks etc. The meshes that connect the platform tracks to in- and outgoing lines could also be further evaluated. Finally, a station design that is hereby found to be feasible should also be evaluated with respect to delay propagation and disturbances.

\section{Acknowledgements}

The analyses presented in this article were performed by the Royal Institute of Technology (KTH) as a consultancy assignment for the Swedish Rail Administration (Banverket). It is part of the planning process for the extension of the Mälar line.

\section{References}

[1] Berg von Linde O., Projekt Tegelbacken - en kapacitetsbetraktelse, Tåg Otto HB Rapport 2002-19, 2002. (in Swedish)

[2] Carey, M., S. Carville, Scheduling and platforming trains at busy complex stations, Transportation Research Part A 37, pp. 195-224, 2003.

[3] Hansen, I.A., Station capacity and stability of train operations, In: J. Allan, R.J. Hill, C.A. Brebbia, G. Sciutto \& S. Sone, (eds.), Computers in Railways VII, pp. 809-816, WIT Press, Southampton, 2000.

[4] Kroon, L.G., H.E. Romeijn, P.J. Zwaenveld, Routing trains through railway stations: complexity issues, European Journal of Operational Research $\mathbf{9 8 ,}$ pp. 485-498, 1997.

[5] Lindfeldt, O., Train traffic in greater Stockholm. The demand for a new twin track railway through Stockholm. In: M.C. Ford (ed.), Proceedings of Railway Engineering $7^{\text {th }}$ International Conference and Exhibition, London, Great Britain, 2004.

[6] Lindfeldt, O., Evaluation of punctuality on a heavily utilised railway line with mixed traffic, In: Allan, J., Arias, E., Brebbia, C.A., Goodman, C.J., Rumsey, A.F., Sciutto, G., Tomii, N., (eds.), Computers in Railways XI, pp. 545-553, WIT Press, Southampton, 2008. 
[7] Lindfeldt O., Analysis of capacity on double-track railway lines, Transport Planning and Technology. In press, 2009.

[8] Schaafsma, A.A.M., M.M.G.P. Bartholomeus, Dynamic traffic management in the Schiphol bottleneck, In: I.A. Hansen, F.M. Dekking, R.M.P. Goverde, B. Heidergott, L.E. Meester (eds.), Proceedings of $1^{\text {st }}$ International Seminar on Railway Operations Modelling and Analysis, Delft, The Netherlands, 2005.

[9] Yuan, J., I.A. Hansen, Optimizing capacity utilisation of stations by estimating knock-on train delays, Transportation Research Part B 41, pp. 202-217, 2007. 